Materials Research Society Vol. IX No. $4 \quad$ July/August 1984

\title{
MRS ELECTIONS
}

\section{The Society's Membership Will Select The Scientists \\ Who Will Provide Leadership In 1985 . . And Beyond}

Members of the Materials Research Society will elect the organization's officers, and five members of its governing council, in elections currently being conducted. Also to be voted on are proposed changes to the Society's Constitution, which establish Student Chapters and Sections. Ballots have been mailed to all members. In this issue of the BULLETIN, election candidates are profiled and the Constitutional changes presented.

\section{Election of Officers and Councilors}

"The election of the Society's officers and members of the governing council is the most important responsibility MRS membership conveys," observes Harry J. Leamy, Chairman of the Nominating Committee. "This year, we are fortunate to have a particularly outstanding cross-section of materials professionals contending for the Society's most important offices. As well as professional excellence, each has demonstrated through prior service to the Society the energy and dedication required to fulfill these offices."

To be elected are the Society's First Vice President, Second Vice President, Secretary, Treasurer, and five Councilors. The Vice Presidents serve one-year terms; the Secretary and Treasurer two-year terms, and the three-year terms of Councilors are staggered so only a third of them are elected each year.

Under the Society's Bylaws, this year's First Vice President, Elton N. Kaufmann, will automatically assume the presidency in 1985 .

Leamy notes that the elections process has been formalized in 1984 through the institution of separate mailing of ballot materials to the Society's current list of active members. Prior elections have been conducted through the BULLETIN.

The proposed changes to the Constitution are described elsewhere in this issue of the BULLETIN.
Grouped below in the order of the offices they seek to fill are candidates of the MRS for 1985:

\section{First Vice President}

\section{GORDON E. PIKE}

Sandia National Laboratories

Albuquerque, NM 87185

(505) $844-9168$

Gordon Pike graduated from Carnegie Mellon University in 1963 with a B.S. in physics. He received the Ph.D. in the same field from the University of Pittsburgh in 1969, and joined Sandia thereafter. At Sandia, his research has involved electronic properties of materials. He has made experimental and theoretical contributions in electronic hopping transport in insulators, superconductivity, radiation effects in MOSFET transistors, percolative conduction in heterogeneous materials, and the electrical properties of semiconductor grain boundaries. $\mathrm{He}$ is a member of the MRS, the APS, and the ACerS.

Gordon is an MRS activist. He served as symposium cochairman for the 1981 symposium on grain boundaries in semiconductors, and subsequently as meeting co-chairman for the 1983 Annual Meeting. At the same 


\section{ELECTIONS}

\section{[Continued from Page 1]}

time, Gordon spearheaded the MRS's effort to establish a Spring Meeting, and was, together with Ross Lemons of Los Alamos and Noble Johnson of Xerox PARC, responsible for its success. His organizational skills are tested and proven. Indeed, Gordon receives high praise from both the Nominating Committee and the MRS Council, who unanimously endorse his candidacy and election.

"Major issues facing the MRS in the near future all arise from the dramatic growth of our Society," Gordon says. "The need for increased international participation in our programming and planning is worthy of attention, as is organization and funding of new and expanded activities. These latter include short courses, publications, and participation as a Society in the international community of scientists. My involvement with the MRS has been both personally rewarding and professionally stimulating. I look forward to a continuation of this pleasurable activity, and your support and cooperation in the important work of the MRS."

\section{Second Vice President}

\section{KATHLEEN C. TAYLOR}

General Motors Research Laboratories

Warren, MI 48090

(313) $575-3089$

Kathy Taylor is head of the Environmental Sciences Department at GM, where she has been employed since 1970. She received the A.B. degree in chemistry from Rutgers University in 1964 and the Ph.D. degree from Northwestern University

Kathy's research

interests

heterogeneous catalysis, surface chemistry, and automobile exhaust emission control. She is a member of the MRS, the ACS, the Chemical Society (London), the Catalysis Society, and the Society of Automotive Engineers.

Kathy Taylor has long been active in MRS activities. She has been a symposium cochairman, an annual meeting co-chairman, councilor, and

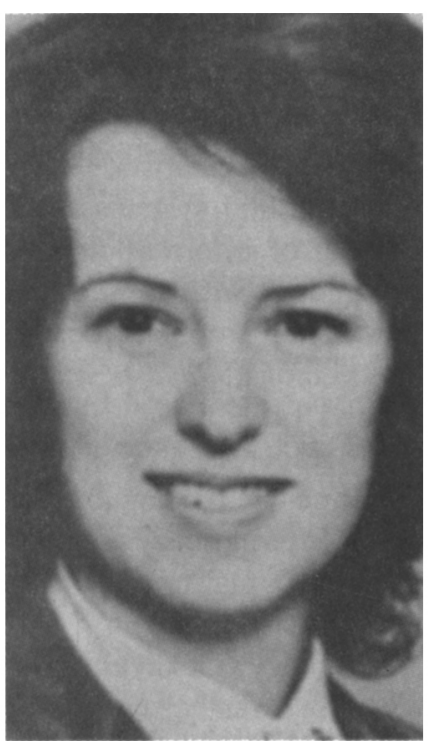

KATHY TAYLOR treasurer, the latter two positions being current. She is also a member of the Awards Committee and the Finance
Committee. Kathy has been treasurer for the Society since 1981, and has managed the financial integrity of the MRS during its recent period of enormous growth. Besides overseeing the Society's financial affairs, she initiated and coordinates the Student Awards Program. This activity has recognized scores of outstanding science and engineering students with assistance and incentives to present papers at the Society's meetings.

\section{PAUL S. PEERCY}

Sandia National Laboratories

Albuquerque, NM 87185

(505) 844-4309

Paul Peercy is Manager of the Ion Implantation and Radiation Physics Research Department at Sandia National Laboratories in Albuquerque, New Mexico. After receiving his PhD degree in Physics from the University of Wisconsin in 1966, Paul joined Bell Laboratories on a post-doctoral appointment. In 1968 he joined the technical staff at Sandia. His research interests have included the physics of semiconductors, plasmas in solids, structural phase transitions and ferroelectricity, Raman and Brillouin Scattering in solids, ion implantation, ion beam analysis, and laser annealing.

Paul is an active member of the Materials Research Society, both as a participant and as an organizer. He was

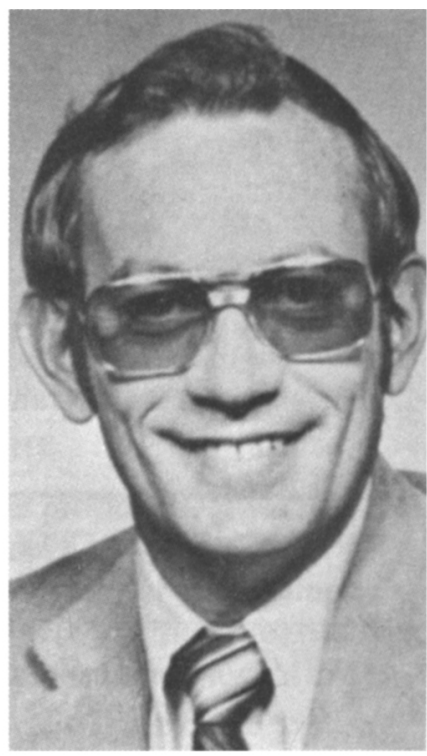

PAUL PEERCY co-organizer of the 1979 MRS symposium on Laser and Electron Beam Processing of Materials and a member of the MRS Membership Committee. He is currently one of the co-chairmen for the 1984 Fall Meeting, to be held in Boston.

\section{Treasurer}

\section{DOUGLAS E. BROOKINS}

University of New Mexico

Albuquerque, NM 87131

(505) $277-2310$

Doug Brookins is Professor of Geology at the University of New Mexico, where he has been located since 1971. He received his A.B. in geology at Berkeley, and the Ph.D. in Isotope Geochemistry from MIT. Doug taught at Kansas 
State University from 196371, where he was named outstanding teacher-researcher in 1970. Since joining UNM, he has served as chairman of the Geology department, has been a visiting staff member at Los Alamos National Laboratory, and has acted as a consultant at the Argonne, Lawrence Berkeley, Lawrence Livermore, and Sandia National Laboratories. His research interests are now largely devoted to problems of radioactive and chemical waste disposal in geologic media. He has recently

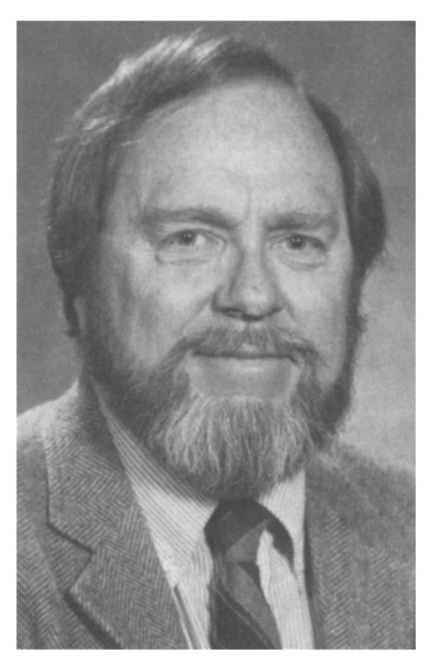

DOUG BROOKINS authored a book, Geochemical Aspects of Radioactive Waste Disposal (Springer-Verlag 1984), in this field as well as editing an MRS proceedings volume on the same topic. An active researcher, Doug has authored two additional volumes and a large number of literature contributions. He also operates and supervises the geochronology laboratory at UNM.

Doug has been an active participant in MRS activities for the past six years. He has served on the program review committee of the Nuclear Waste Management symposium for four of those years, and was program chairman of the symposium in 1982. During this year, Doug was presented with the society's outstanding chairman award. $\mathrm{He}$ is a member of the Membership Committee, the Publications Committee, and has contributed to the BuLlETIN on the subject of radioactive waste.

"I feel that the MRS is a most exciting group, as reflected in part in the tremendous growth of the Society over the last few years," he says. "I hope to continue to be active in the Society and to help it blossom in any way possible in the future."

\section{CLIFTON W. DRAPER}

Engineering Research Center

AT \&T Technologies, Inc.

Princeton, NJ 08540

(609) 639-2350

Clif Draper is Group Leader - Lightguide Materials at AT \& T Technologies' ERC. A chemist, Clif received the B.S. degree from SUNY-Albany in 1970, spent three years on USAF C-141 Starlifters, and returned to Penn. State, where he received the Ph.D. in physical chemistry in 1977. His research interests include energy transfer at solid surfaces, high temperature processes, rapid solidification, surface modification of metals, and defect studies in laser irradiated single crystals. Clif collaborates with colleagues from Princeton, SUNY-Stony Brook, the University of Pennsylvania, the University of Illinois, Clark University, the University of Rhode Island, AT\&T Bell Laboratories,

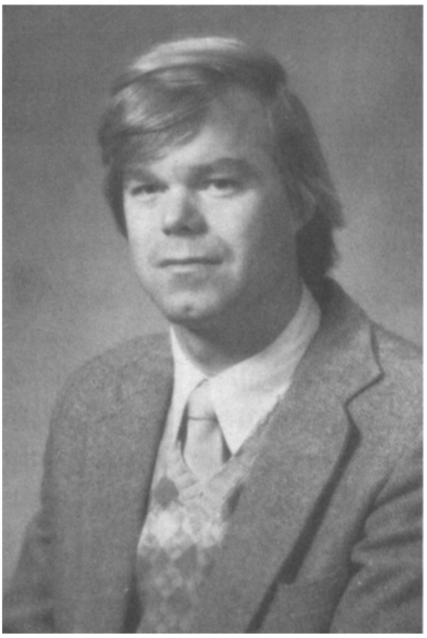

CLIF DRAPER

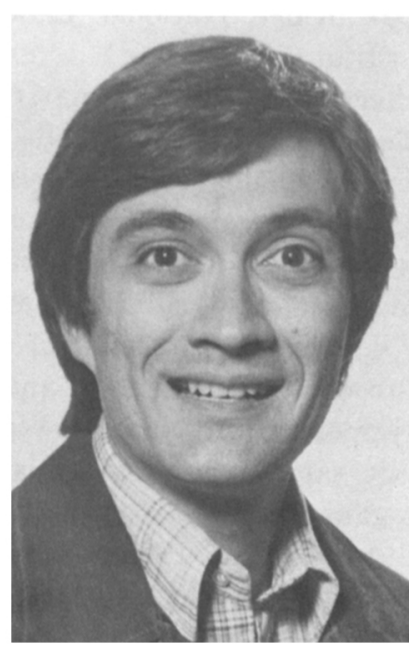

ROD EWING and Lawrence Livermore National Laboratory. $\mathrm{He}$ is a member of the MRS, the ACS, the ACerS, the OSA, and the Laser Institute of America.

A member of the MRS since 1978, Clif has participated in four different symposia. He was named a member of the Corporate Participation Committee in 1983, and was asked to chair the committee during 1984. During his tenure, corporate participation in the MRS reached record numbers, both in total membership and dollars for MRS activities.

"Future direction of this unique experiment, the MRS, will continue to depend on a relatively few people in key positions devoting a considerable quantity of time, for a great cause and with little reward in return," Clif says. "God knows why, but I am willing to do it."

\section{Secretary}

\section{RODNEY C. EWING}

University of New Mexico

Albuquerque, NM 87131

(505) 277-4204

Rodney C. Ewing is Professor of Geology at the University of New Mexico. A native of Texas, he received the B.S. degree in geology from Texas Christian University, and the M.S. and Ph.D. degrees in the same field from Stanford University. Upon leaving Stanford, Rod joined the geology department at UNM, where he has served as assistant professor, associate professor, and where he is currently Chairman of the Department of Geology. Rod is a fellow of the Geological Society of America, and the Mineralogical Society of America. He is a member and councilor of the MRS and a past president of the New Mexico Geological Society. He also holds membership in the Electron Microscopy Society of America, the Mineralogical Association of Canada, AAAS, and Sigma $\mathrm{Xi}$. Rod has served as associate editor of the American Mineralogist, and as a member of the Board of Directors of Energy, Exploration, Education, Inc. He has also been a visiting scientist at Battelle Pacific Northwest Laboratories, 
Oak Ridge National Laboratory, and the Hahn-Meitner Institute in Berlin. His research interests include radiation effects in crystalline materials, the mineralogy and crystal chemistry of complex Nb-Ta-Ti oxides, the application of natural analogues to the evaluation of the long term stability of radioactive waste forms, low temperature corrosion of silicate glasses, and the application of synchrotron radiation to the study of radiation damaged materials.

Currently a councilor of the MRS, Rod has served on the Program Committee, and has co-organized an MRS symposium on Nuclear Waste Management. He co-chairs this same symposium this year in Boston, and will help organize another symposium on this topic to be held in Stockholm in 1985. Rod is currently a member of the Nominating Committee of the MRS, and is also cochairman of the Education Committee.

Rod says, "I am pleased to serve as an active member of the MRS, as I think that it is one of the most interdisciplinary societies in the world. The mix of disciplines is extraordinary, and as someone educated in mineralogy/crystallography, this has been of great benefit to me in my research, and a personal pleasure."

\section{DON E. HARRISON}

Westinghouse R \& D Center

Pittsburgh, PA 15260

(412) 256-1200

Don Harrison is manager of the Materials Science Division at Westinghouse, where he has been employed for the last 25 years. A ceramist by training, he obtained the B.S., M.S., and Ph.D degrees from The Pennsylvania State University. His division at Westinghouse is active in the areas of nuclear fuel cycle and ceramic technology, metals joining, physical metallurgy, materials testing, and corrosion research. In recent years, Don has been active in the application of sol-gel technology to the immobilization of high level nuclear waste.

Don's involvement with the MRS stems from his interest in sol-gel technology. It was he, in cooperation with Rustum Roy, who initiated MRS activity in the field by organizing the symposium "Ceramics from Solution: Sol-Gel and Fine Particle Technology."

"During a period of rapid change, participation in the activities of the MRS is especially important since it is consistently among the first to recognize emerging technologies," he notes.

\section{Members of Council}

\section{BILL R. APPLETON}

Oak Ridge National Laboratory

Oak Ridge, TN 37830

(615) 574-6283

Bill is a Section Head in the Solid State Division at Oak Ridge, where he directs and performs research into ion-solid interactions, ion implantation doping and the use of ion beam and laser processing for the alteration and analysis of materials. Most recently, he has been named director of the Surface Modification and Characterization Collaborative Research Center at Oak Ridge (see the last issue of the BULLETIN).

Appleton received the Ph.D. degree from Kutgers University, worked at Bell Laboratories in Murray Hill for two years, and then joined Oak Ridge in 1969. He has published more than 125 articles, reviews and book chapters. $\mathrm{He}$ is a fellow of the APS, a member of the AAAS, SESAPA, Bohmische Physikalische Gesellschaft, and the MRS.

Bill has served the MRS as a symposium chairman, member of the Nominating Committee, the Corporate Participation Committee, Program Committee, and was cochairman of last year's Annual Meeting. In addition, Bill served as MRS Second Vice President during 1984, and was an active promoter of its activities during the last twelve months. Because his new duties at Oak Ridge promise to leave him little scope for active participation as First Vice President, Bill has declined to stand for election to that office.

According to Bill, "The MRS is an exciting, active, and dynamic young organization whose growth demands of its officers a significant time commitment. I am proud to have been an active participant in the MRS Executive Committee, and feel strongly about the future of our Society. In fact, it is my strong belief in the importance of the MRS that prompts me to stand for the less active role of councilor, rather than run for the President-elect position."

\section{WALTER L. BROWN}

AT\&T Bell Laboratories

Murray Hill, NJ 07974

(201) $582-3941$

Walter is Head: Radiation Physics Research Department at Bell Labs. He graduated from Duke University with a
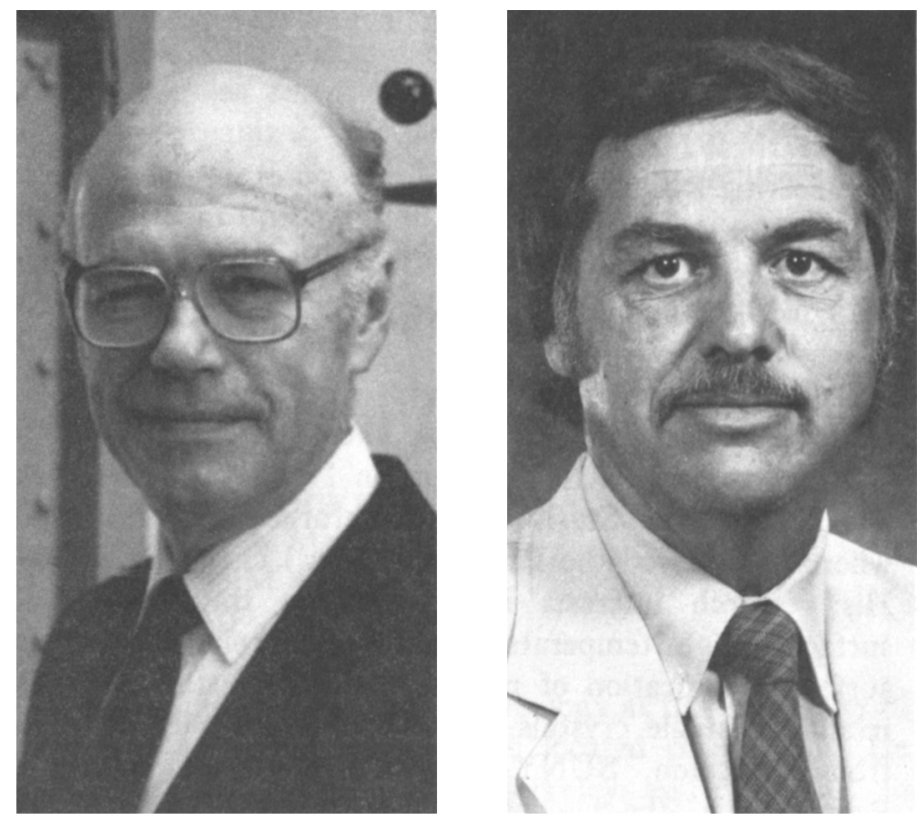

DON HARRISON
BLLL APPLETON 
B.S. in physics in 1945, and received the $\mathrm{Ph} . \mathrm{D}$. degree in the same field from Harvard in 1951. He joined Bell Labs immediately upon graduation. Walter's research activities are quite broad, and include study of surface states on semiconductors, radiation produced defects in semiconductors,

semiconductor particle detectors, radiation in space, ion beam channeling, ion implantation, alloy sputtering, laser annealing, electronic sputtering, and liquid metal ion sources. He is a member of the MRS, the AAAS, and is a fellow of the APS.

Walter has been an active participant in MRS affairs since 1978, when he participated in the Society's first symposium on laser-solid interactions. His activities in this symposium led to the co-chairmanship of the event in 1982 with Jagdish Narayan and Ross Lemons. Currently a member of the Awards Committee and the Program Committee, Walter has been active in the selection of student award recipients. This year, he has assumed responsibility, together with Paul Peercy and Jagdish Narayan, for the Society's Annual Meeting in Boston.

\section{MILDRED S. DRESSELHAUS}

Center for Materials Science \& Engineering

Massachusetts Institute of Technology

Cambridge, MA 02139

(617) 253-6864

Mildred Dresselhaus, who as President of the American Physical Society has been outspoken in her support for the Materials Research Society, its meetings, and its goals, holds the Abby Rockefeller Mauze Chair in Electrical Engineering and Computer Science and Physics at the Massachusetts Institute of Technology. She also is affiliated with the Center for Materials Science and Engineering of MIT, which she formerly directed.

Aside from her service at the helm of APS, Mildred serves on numerous advisory committees of the National Research Council and other federal agencies. She has been active in the study of a wide range of problems in the physics of solids. Her recent interests have been directed toward the modification of the properties of electronic materials and graphite fibers by intercalation and implantation.

A current member of the MRS Long Range Planning Committee, Mildred has an interest in the course of our Society as it matures, and the role that it will play in the scientific community at large.

ROSS A. LEMONS

Electronics Division

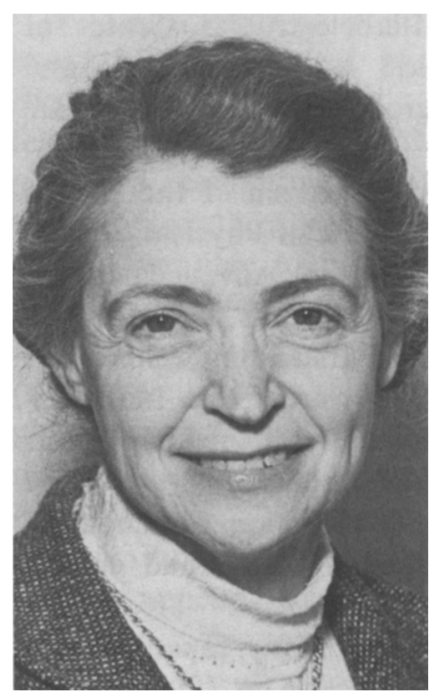

MILDRED DRESSELHAUS

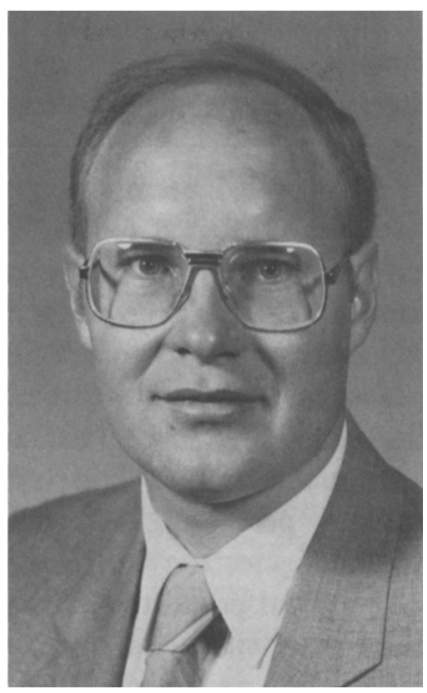

ROSS LEMONS
Los Alamos National Laboratory

Los Alamos, NM 87545

(505) 667-6832

Ross is leader of the Electronics Research Group at Los Alamos National Laboratory. He received his B.A. from the University of Colorado in 1970 and his M.S. and Ph.D. in applied physics from Stanford University in 1972 and 1975, respectively. While at Stanford, he invented the scanning acoustic microscope. As a member of the technical staff at Bell Laboratories from 1976 to 1982, he worked on electrochromic displays, magnetostatic waves, ferroelectricferroelastic devices, thin-film silicon crystallization, and optical recording. He joined the electronics division at Los Alamos in 1982, where he currently manages research projects on fuel cells for transportation, thermionic integrated circuits, high-speed photoconductors, pulse power, ion beam analysis, and laser processing of materials.

Ross has been a member of the MRS since 1980. In 1982 , he served as co-chairman of the symposium on lasersolid interactions and transient thermal processing of materials. In 1984, he was a general co-chairman of the Society's inaugural Spring Meeting, held in Albuquerque. At present, he is a member of both the Program and Finance committees of the Society.

\section{JAGDISH NARAYAN}

Microelectronics Center of North Carolina

Research Triangle Park, NC 27709

Jay Narayan, who is general co-chairman of this year's Annual Meeting of the MRS, received his B.S. degree in metallurgy in 1969 from the Indian Institute of Technology, Kanpur, India, and obtained the M.S. and Ph.D. degrees in materials science from the University of 'California at Berkeley in 1970 and 1971, respectively. After spending a year at the Lawrence Livermore National Laboratory as a research metallurgist, he joined Oak Ridge National Laboratory, where until his recent appointment as director 
of materials research at the Microelectronics Center of North Carolina, he was leader of the defects and interfaces/electron microscopy group in the solid state division.

Jagdish, who became a naturalized citizen of the United States in 1981, is a fellow of the American Physical Society and the American Association for the Advancement of Science. He has received a number of awards, including the U.S. Department of Energy's Outstanding Sustained Research Award, and three IR-100 Awards from Industrial Research Magazine. His research interests include defects in semiconductors, laser-solid interactions and transient thermal processing of materials, radiation damage in materials, electron diffraction and microscopy, and defects and physical properties of materials.

Jay Narayan has served the MRS in many capacities. In 1980, he initiated the symposium on defects in semiconductors, a series that has become among the most popular offered at MRS meetings. In 1982, he was cochairman of the symposium on laser-solid interactions and transient thermal processing of materials. In 1983, he helped in the organization of the symposium on defect properties and processing of high-technology nonmetallic materials. This year, he is a general meeting co-chairman of the Annual Meeting.

"I would like very much to continue serving the Society," he says. "Present and future advances in technology depend very much on the availability of novel and improved materials. The Materials Research Society is in a unique position to play an important role in bridging the gap between fundamental sciences and technological applications, which is needed for developing advanced materials."

\section{CLYDE J. M. NORTHRUP, Jr.}

Sandia National Laboratories

Albuquerque, NM 87185

(505) 844-5650

Clyde is a member of the Future Options Group at Sandia, where he takes part in strategic, long range program planning activities. Previously, he was Division Supervisor of the Chemical Technology Division, in which he managed work on new ceramic materials and nuclear waste forms, and the study of transport phenomena. He has also performed research on metal hydrides, radiation effects in solids, hydrogen production from magma, and solar engines. He received a $\mathrm{Ph} . \mathrm{D}$. in physics from Oklahoma State, and has undergraduate degrees in mathematics and physics.

An MRS stalwart, Clyde has served as symposium cochairman, meeting co-chairman, Vice President, President, Past President, and as Chairman of the Long Range Planning Committee, the Awards Committee, and the Nominating Committee. Currently, Clyde serves the MRS as Chairman of the Finance Committee.

"I believe the Society should provide a leadership role in guiding the understanding of materials and materials processing," Clyde says. "This is best accomplished by

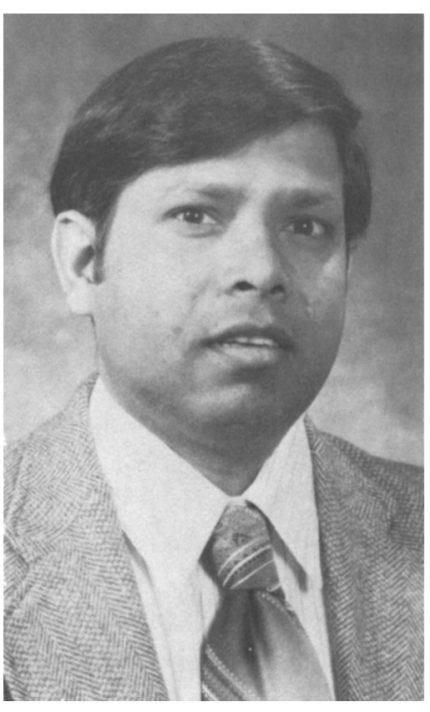

JAY NARAYAN

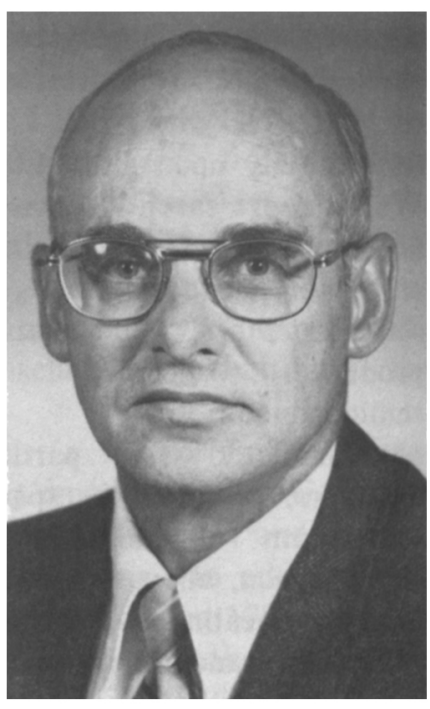

CLYDE NORTHRUP providing materials scientists with various forums to exchange information and to critically review results. It should also assist in the development of computerized materials data bases. Many of the techniques that materials scientists are now using can be expected to change dramatically in the next ten years and the MRS should provide training both in the form of short courses and workshops. This year, I participated in formulating major changes in the publication strategies of the Society that will lead to a reduction in costs and distribution time. I would like to see this trend continue and be extended to include low cost reference and teaching materials."

\section{GEORGE A. ROZGONYI}

Materials Engineering Department

North Carolina State University

Raleigh, North Carolina 27695-7907

(919) 737-2934

George received the B.S. degree in Aeronautical Engineering and an M.S. in Engineering Science from the University of Notre Dame in 1958 and 1960. His Ph.D. in 1963 in Aero-Space Sciences at the University was based on "Field Emission from in-situ Grown Copper Whiskers." From 1963 to 1982 he was affiliated with various semiconductor materials preparation and device technology departments at Bell Laboratories in Murray Hill, N.J. Between 1979 and 1981 he was on sabbatical at the Max Planck Institute for Solid State Physics in Stuttgart, Germany, and the French National Microelectronics Center (CNET) in Grenoble, France. In 1982 he received a joint appointment as Microelectronics Research Professor at North Carolina State University, and Director of Semiconductor Materials at the Microelectronics Center of North Carolina.

He holds nine patents, has published over 100 technical papers, seven book chapters, and has also edited three books. Society affiliations include the MRS, the Electrochemical Society, the APS, and the American Association for Crystal 


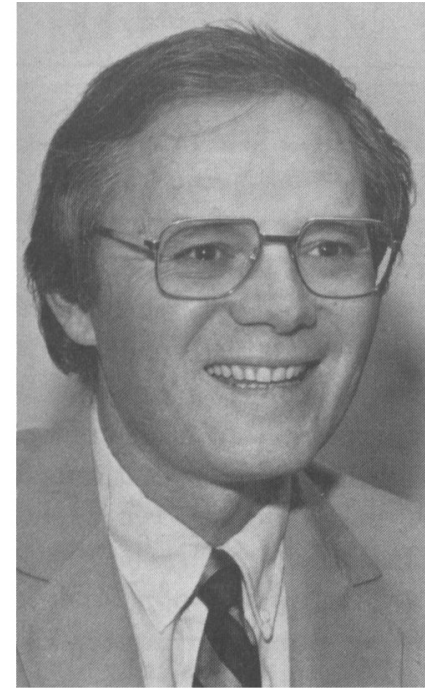

GEORGE ROZGONYI

FRED YOUNG

Growth. In 1981 George received the Electronics Division Award for the Electrochemical Society in recognition of his important contributions to electronic materials, particularly in the area of crystal defects in device processing.

George is a co-chairman of the 1984 Energy Beam - Solid Interactions and Transient Thermal Processing symposium, and was instrumental in organizing the first regional MRS chapter in North Carolina.

"If elected councilor," he says, "I would work to increase the coordination between symposia with overlapping topic areas (as has been done this year for symposia $A$ and $C$ ), use regional MRS chapters to act as feeders for new members to sustain and enrich the volunteer worker troops, and finally, I would like to see the costs for attending MRS conferences reduced to a more reasonable level."

FRED W. YOUNG, Jr.

Oak Ridge National Laboratory

Oak Ridge, TN 37830

(615) 574-5501

Fred Young is Associate Director, Solid State Division, Oak Ridge National Laboratory. A Virginian, Fred received the B.S. degree from Hampden-Sydney College in 1944, and the Ph.D. from the University of Virginia in 1950. He joined Oak Ridge as a Research Associate upon graduation, returned to the University of Virginia to spend five years there as a Research Associate, and returned to Oak Ridge in 1956. His affiliation with Oak Ridge has since remained unbroken, save a year in 1975-76, when he was a Guest Scientist at KFA-Julich, in the Federal Republic of Germany.

Fred Young's research interests include laser annealing, defects in solids, crystal growth, radiation effects, defect characterization by $\mathrm{x}$-ray scattering, deformation of solids, and the oxidation of metals. He has served as organizer or organizing committee member for many national and international conferences and workshops, and has also organized numerous workshops and panels on behalf of the
U.S. Department of Energy. Fred served on the editorial board of the Journal of Applied Physics, and Applied Physics Letters during the period from 1977-1980. He is a fellow of the APS and the AAAS, is a member of the executive committee of the American Association for Crystal Growth, a member of the MRS, and the American Crystallographic Association.

"It is widely recognized that strength in materials science is vital to the economic well-being and the future development of the United States," he says. "The phenomenal growth of the Materials Research Society is clear evidence that this Society is playing a vital role in the dissemination of scientific information and in stimulating communication between materials scientists. The symposia format appears to assure continuing success for MRS meetings. A task now before the Society is the establishment of a sound financial structure to support its expanding activities. Also, the Materials Research Society must assume its proper role in aiding the resolution of the complex issues facing materials science on the national and international scale. I would plan to take an active role in these efforts."

\section{MIRS BULLETIN}

VOLUME IX

NUMBER 4

The Materials Research Society BULLETIN is published bi-monthly by the Materials Research Society for its members and others interested in materials science. Correspondence and submissions are invited. They should be brief and typewritten (double-spaced), and the author's affiliation must be indicated. Address all material to the Editor.

President C.W. WHITE Oak Ridge National Laboratory Vice President E.N. KAUFMANN Lawrence Livermore National Laboratory

Vice President B.R. APPLETON Oak Ridge National Laboratory Secretary R.L. SCHWOEBEL Sandia National Laboratories

Treasurer K.C. TAYLOR GM Research Laboratories

Past President H.J. LEAMY AT\& T Bell Laboratories

Executive Director J.B. BALLANCE Materials Research Society, 9800 McKnight Road, Suite 327, Pittsburgh, PA 15237, (412) $367-3003$

MRS-Europe Secretariat Centre de Recherches Nucleaires Laboratoire PHASE

F-67037 Strasbourg Cedex France

Attention: P. Siffert

Telephone: (88) 286543

Telex: CNRS CRO $890032 \mathrm{~F}$

Editor T.G. MIDDLETON P.O. Box $K$, Short Hills, NJ 07078, (201) 467-0504 